\title{
Design and simulation of a normalized fuzzy logic controller for the quadruple-tank process
}

\author{
Wameedh Riyadh Abdul-Adheem \\ Department of Electrical Power Engineering Techniques, Al-Mamoun University College, Iraq
}

\begin{tabular}{l}
\hline \hline Article Info \\
\hline Article history: \\
Received Aug 10, 2019 \\
Revised Oct 9, 2019 \\
Accepted Nov 6, 2019 \\
\hline Keywords: \\
Quadruple tank \\
Multivariable system \\
PI controller \\
Industrial process \\
Fuzzy control
\end{tabular}

\begin{abstract}
Industrial processes include multivariable systems and nonlinearities. These conditions must be effectively controlled to ensure a stable operation. A proportional-integral-derivative controller and other classical control techniques provide simple design tools to designers, but cannot accommodate nonlinearities in industrial processes. In this study, the quadruple-tank process, which is one of the most widely used processes in the chemical industry, was selected as the research object. To examine this process, a fuzzy logic controller, instead of an exact mathematical model, was proposed to ensure the reliability of the experience. A modification was proposed to facilitate the design process. To check the validity of the proposed controller, it was compared with the conventional proportionalintegral controller. The former exhibited acceptable performance.
\end{abstract}

Copyright $\odot 2020$ Institute of Advanced Engineering and Science. All rights reserved.

\section{Corresponding Author:}

Wameedh Riyadh Abdul-Adheem,

Department of Electrical Power Engineering Techniques,

Al-Mamoun University College, Baghdad, Iraq

Email: wameedh.r.abduladheem@almamonuc.edu.iq

\section{INTRODUCTION}

Processes in the chemical industry exhibit nonlinear and highly complex dynamics. These processes also include multi-input and multi-outputs models with high uncertainties and interactions of inputs and dynamics [1]. The quadruple-tank process (QTP) is a multivariable process that includes a pair of inputs and a pair of dual outputs [2].

In the past decade, many mechanisms and control techniques have been used to build QTP controllers. These techniques include the predictive model controller [3-7], multiparametric quadratic programming-based controller [8], $H_{\infty}$ loop-shaping controller [9], fractional-order proportional-integralderivative (PID) controller [10-14], fractional-order sliding-mode controller [15, 16] , nonlinear backstepping controller with an adaptive high-gain observer [17], decoupling multivariable systems based on generalized predictive control [18], robust relay-based PID auto-tuning strategy [19], fuzzy aggregated multiparametric model predictive controller [20], novel self-tuning dual-mode adaptive fractional-order proportional-integral (PI) controller with an adaptive feedforward controller [21], and nonlinear state feedback decoupling method [22].

In this study, the inputs of a fuzzy logic controller (FLC) are set as the error and its derivative. Input calculations include the normalization of actual inputs into the universes of discourse of the corresponding linguistic variables using a normalization gain. Similarly, the calculated output is denormalized into the actual physical domain of the control action using a denormalization gain. The normalization and denormalization gains are closely related to conventional controller gains and directly influence closed-loop stability.

The remainder of this paper is organized as follows. Section 2 presents the mathematical model of the QTP. Section 3 proposes an FLC for the control process. The numerical simulations are provided in Section 4. Conclusions are drawn in Section 5. 


\section{QUADRUPLE-TANK PROCESS (QTP)}

A schematic of the QTP is shown in Figure 1. The QTP includes two water pumps that are used to push the flowing water into four tanks through two valves in the ratios of $\gamma_{1}$ and $\gamma_{2}$ [8]. The pumps are driven through control signals $u_{1}$ and $u_{2}$, which are the voltage levels applied to each pump. The water level in each tank is denoted as $h_{1}, h_{2}, h_{3}$, and $h_{4}$ [7]. To generate the output signals $y_{1}$ and $y_{2}$, two level sensors are mounted on the two lower tanks. These sensors are used to measure $h_{1}$ and $h_{2}$. The primary objective of this work is to control the water level in tanks 1 and 2 using input signals $u_{1}$ and $u_{2}$ [2]. The nonlinear mathematical model of the QTP is given as:

where $f(h)=\left(\begin{array}{c}\dot{h}=f(h)+b u, \\ -\frac{a_{1}}{A_{1}} \sqrt{2 g h_{1}}+\frac{a_{3}}{A_{1}} \sqrt{2 g h_{3}} \\ -\frac{a_{2}}{A_{2}} \sqrt{2 g h_{2}}+\frac{a_{4}}{A_{2}} \sqrt{2 g h_{4}} \\ -\frac{a_{3}}{A_{3}} \sqrt{2 g h_{3}} \\ -\frac{a_{4}}{A_{4}} \sqrt{2 g h_{4}}\end{array}\right), b=\left(\begin{array}{cc}\frac{\gamma_{1} k_{1}}{A_{1}} & 0 \\ 0 & \frac{\gamma_{2} k_{2}}{A_{2}} \\ 0 & \frac{\left(1-\gamma_{2}\right) k_{2}}{A_{3}} \\ \frac{\left(1-\gamma_{1}\right) k_{1}}{A_{4}} & 0\end{array}\right)$,

$u=\left(u_{1}, u_{2}\right)^{T}, h=\left(h_{1}, h_{2}, h_{3}, h_{4}\right)^{T}$, and $y=\left(y_{1}, y_{2}\right)^{T}=\left(h_{1}, h_{2}\right)^{T}$.

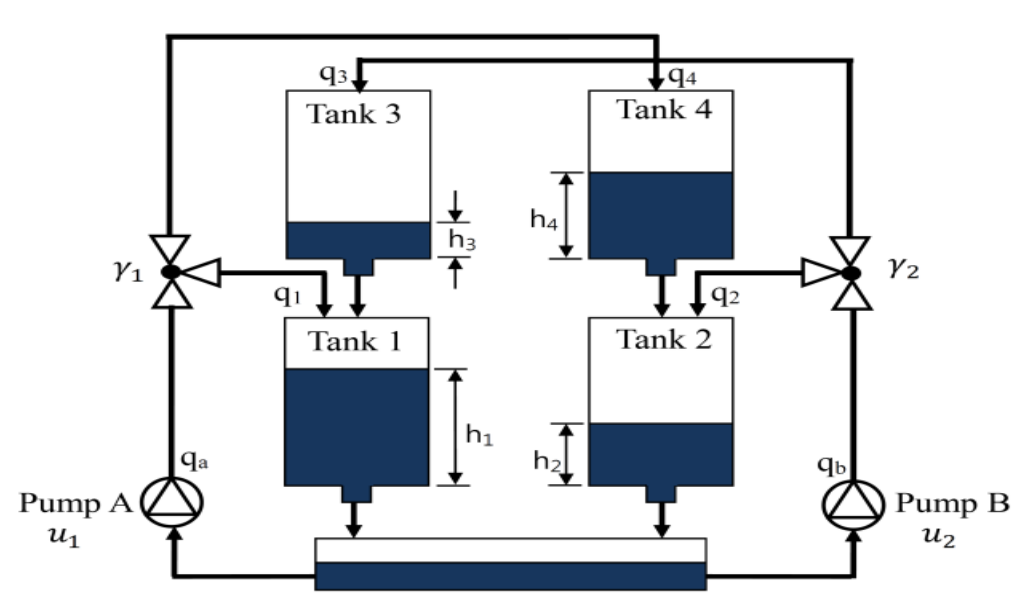

Figure 1. Schematic of the QTP [2]

The values of the parameters of the QTP model are listed in Table 1.

Table 1. Nominal values of the Simulation Parameters $[1,14]$

\begin{tabular}{lcc}
\hline \multicolumn{1}{c}{ Variable } & Description & Value \\
\hline$A_{1}, A_{3}$ & Area of tanks 1 and 3 & $28 \mathrm{~cm}^{2}$ \\
$A_{2}, A_{4}$ & Area of tanks 2 and 4 & $32 \mathrm{~cm}^{2}$ \\
$a_{1}, a_{3}$ & Area of outlet pipes 1 and 3 & $0.071 \mathrm{~cm}^{2}$ \\
$a_{2}, a_{4}$ & Area of outlet pipes 2 and 4 & $0.057 \mathrm{~cm}^{2}$ \\
$g$ & Gravitational constant & 9.81 \\
$\gamma_{1}$ & Flow ratio & 0.7 \\
$\gamma_{2}$ & Flow ratio & 0.6 \\
\hline
\end{tabular}




\section{Normalized FLC (NFLC)}

To address the problems associated with classical control, including nonlinearity and time-varying parameters, a control system that incorporates human experience into decision-making based on uncertain inputs should be adopted [23]. On the basis of human experience, the FLC is used to control processes in the absence of an accurate process model. The basic units of the controller are illustrated in Figure 2.

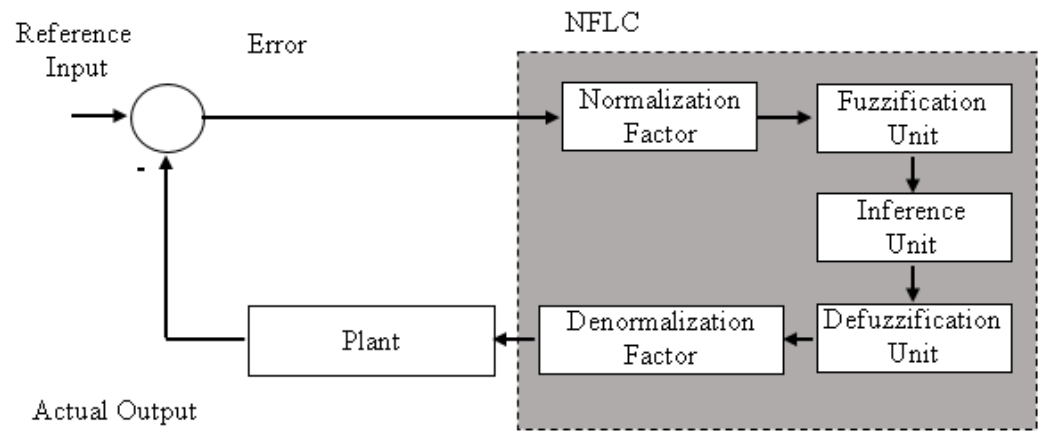

Figure 2. Components of the FLC with normalization and denormalization factors

The function of the fuzzification unit is to convert the values of a crisp input into linguistic variables. Meanwhile, the inference unit plays a role in decision-making. The IF-THEN rules construct the knowledge-based FLC. The result of the fired rules is changed into values that will produce crisp values again [23]-[26]. The minimum and maximum values of the input/output variables determine the universes of these variables. Practically, dealing with a normalized universe of discourse is more convenient than dealing with a real line. This step is performed using normalization and denormalization factors.

A fuzzy inference system (FIS) is designed and implemented to control the QTP. The Mamdani FIS comprises two inputs, one output, and nine rules, which are implemented using MATLAB® Fuzzy Logic Toolbox 2012a. Information about the FIS is found in the FIS editor (Figure 3).

Two inputs are described in the designed FLC. The first input is the error (e), which is the difference between the reference and the actual water levels. The second input is the change rate of the error (de). The output is denoted as " $u$ ". Figure 4 presents the membership editor tool used to edit the membership functions of all the input and output variables. All the membership functions are set as triangle functions with a normalized range $[-1,1]$.

The control action $u$ taken by the controller is determined in accordance with the rules of the FIS. The nine rules are implemented using the rule viewer in Figure 5. The controller output surface is observed using the surface viewer as shown in Figure 6.

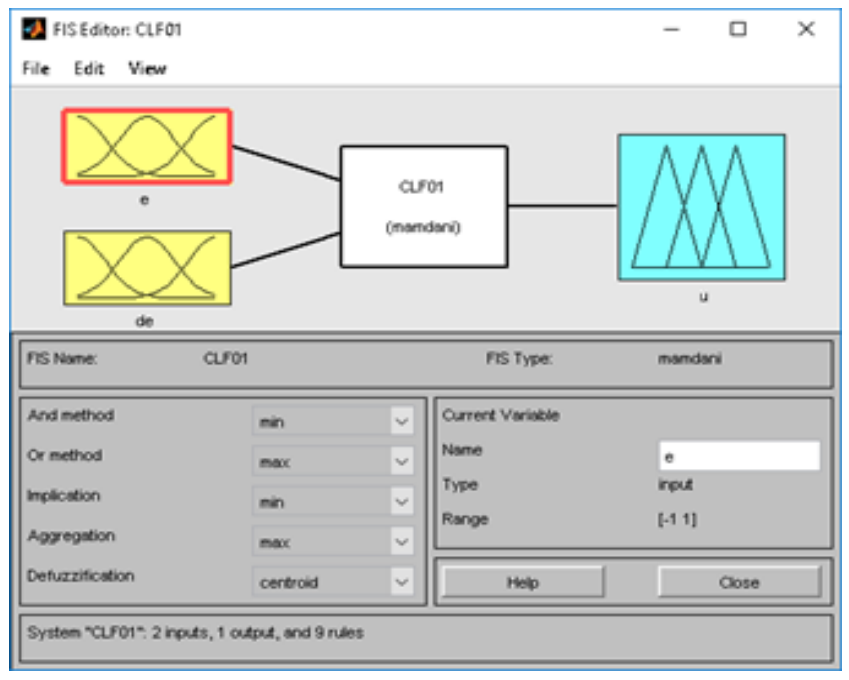

Figure 3. FIS editor 


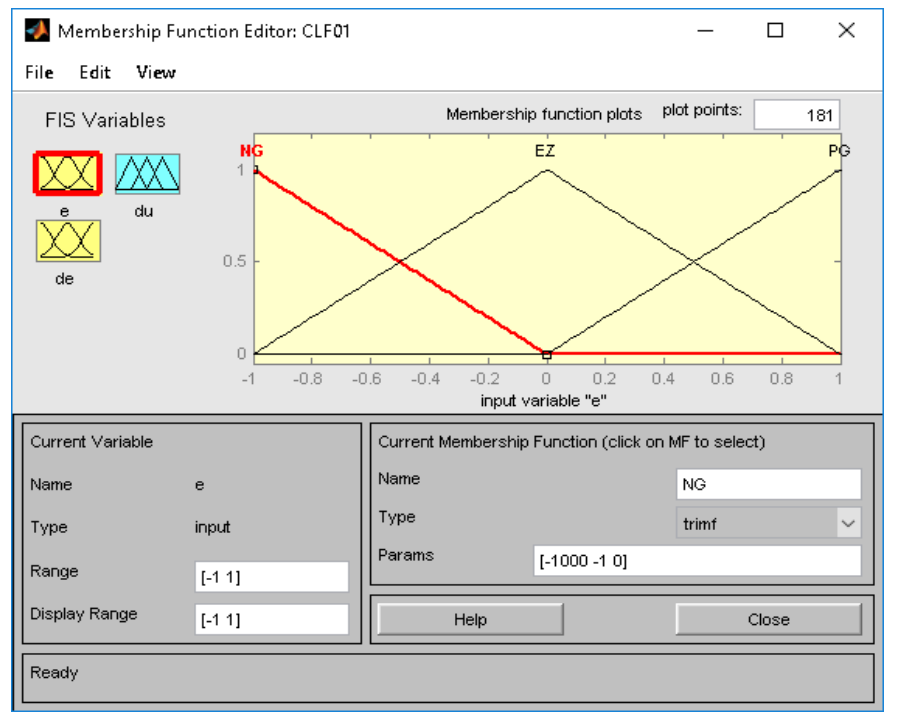

(a)

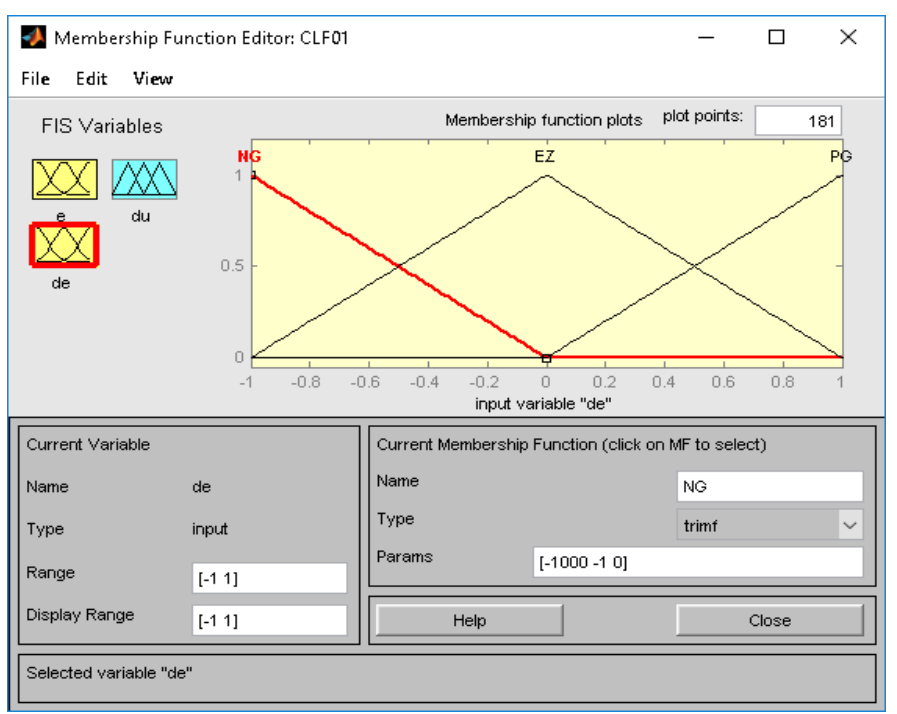

(b)

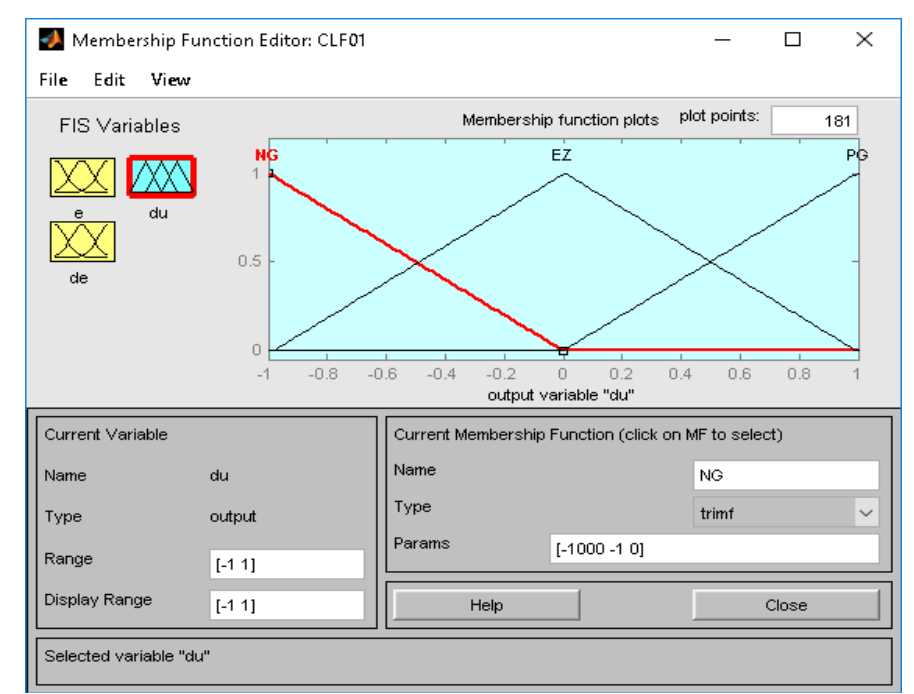

(c)

Figure 4. Membership editor: (a) first input variable, (b) second input variable, and (c) output variable 
The SIMULINK® implementation of the complete model is illustrated in Figure 7. The detailed models are presented in Figures 8 and 9, and the response curves are shown in Figures 10 and 11. The energy values delivered by the implemented controllers to the QTP are listed in Table 2.

Table 2. Energy Values Delivered by the Controllers to the QTP

\begin{tabular}{ccc}
\hline Controller/Energy & $u_{1}$ & $u_{2}$ \\
\hline PI & 10364.76 & 14802.85 \\
NFLC & 2406.5 & 5243.14 \\
\hline
\end{tabular}

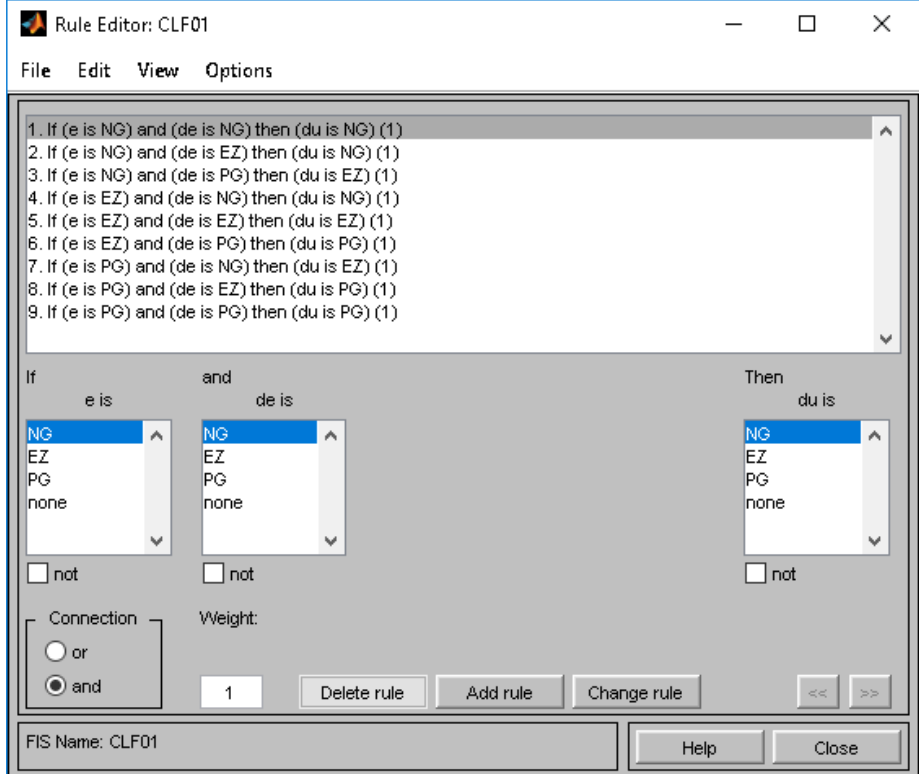

Figure 5. Rule editor and the implemented rule table

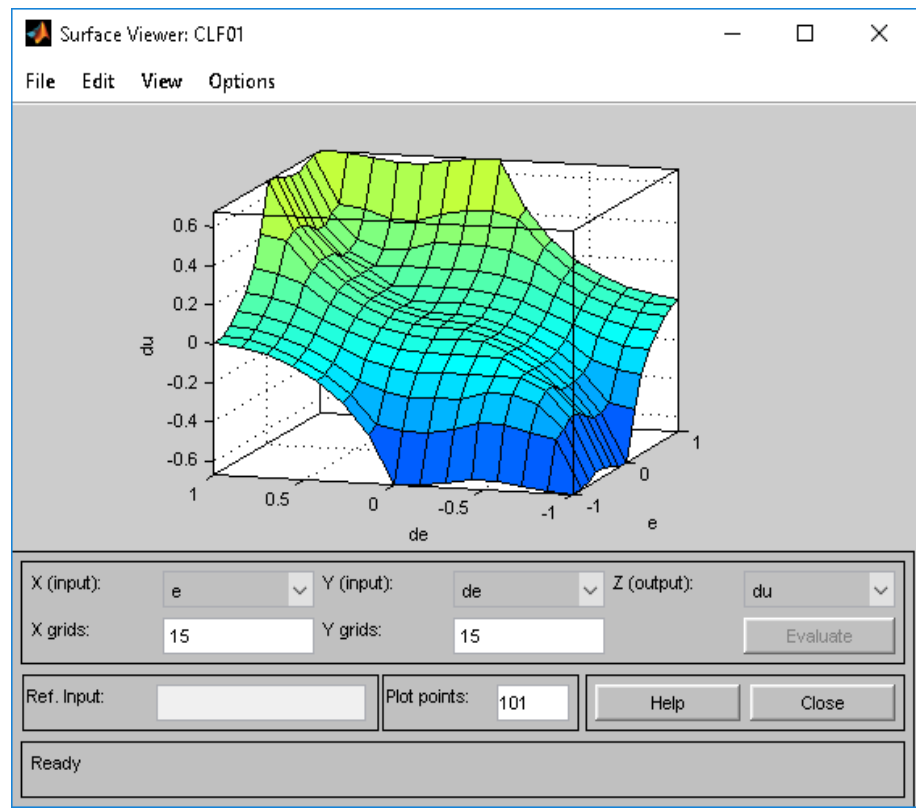

Figure 6. Surface viewer window for rules 
Figure 10 use of a proportional-integral (PI) controller causes an overshoot in response to a steptype reference signal. The percentages of the overshoot of each output are $8 \%$ and $11.3 \%$. By contrast, using the proposed NFLC improves the time response by eliminating the overshoot in the first case. Improvements are not limited to the time response but are extended to the reduction of the energy delivered by the controller to the process. This discussion is summarized in Figure 11 and Table II. The amount of energy that passes to the process in the beginning of the transient is considerably lower in the case of the NFLC than that in the PI controller. The reduction percentages for the channels are $76.78 \%$ and $64.58 \%$, respectively.

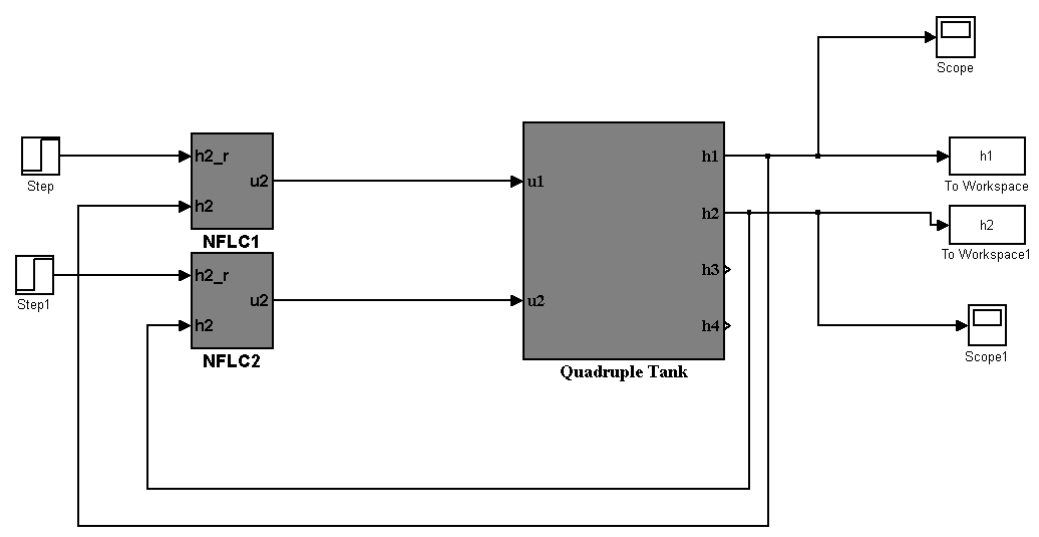

Figure 7. Complete SIMULINK® model of the control system

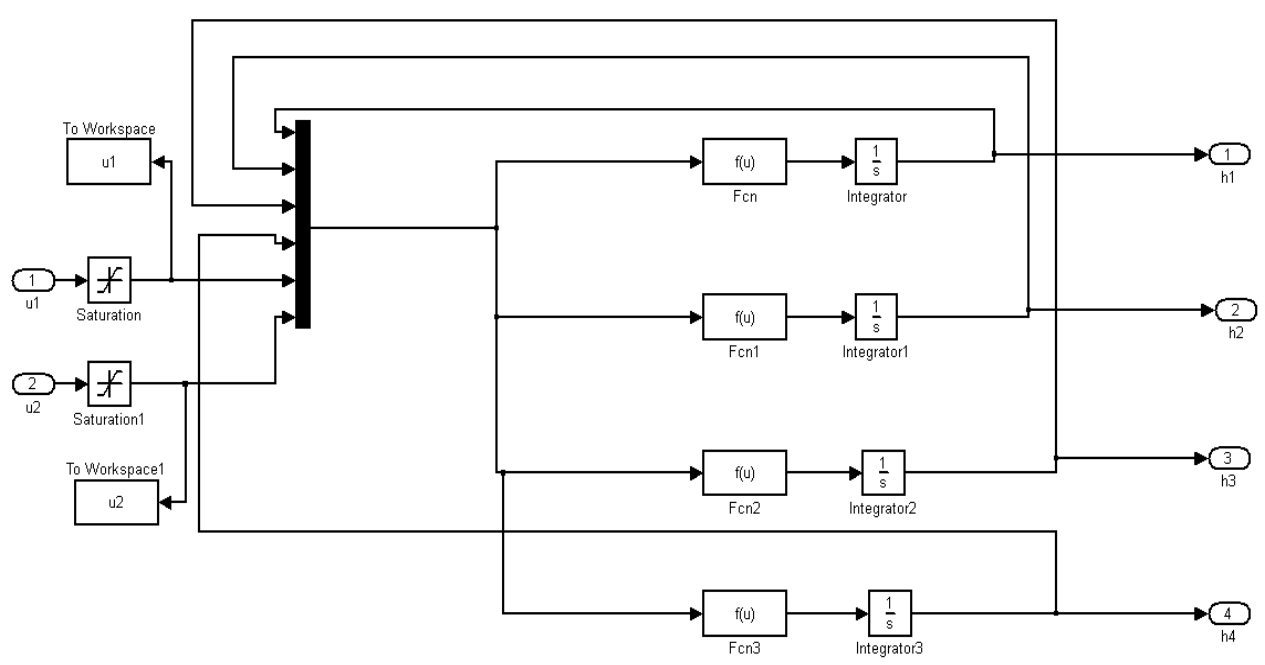

Figure 8. SIMULINK® model of the QTP

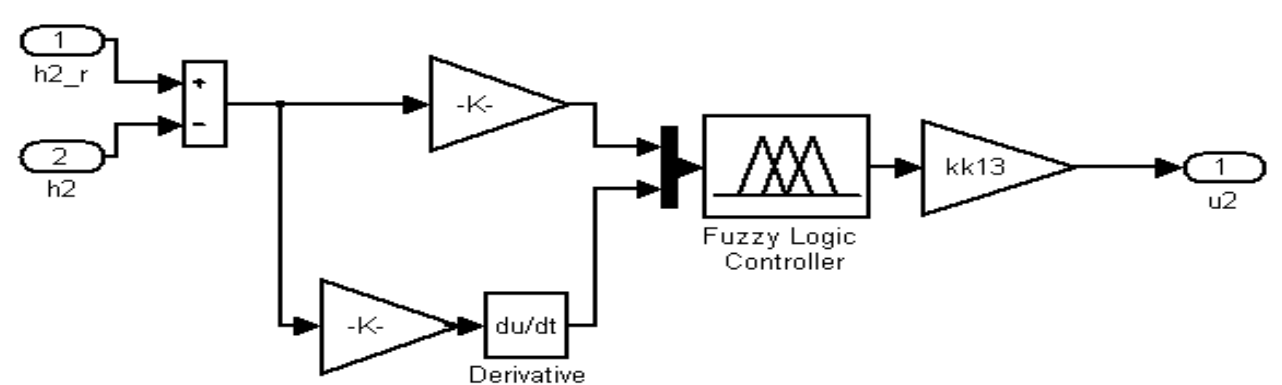

Figure 9. SIMULINK® model of the NFLC 

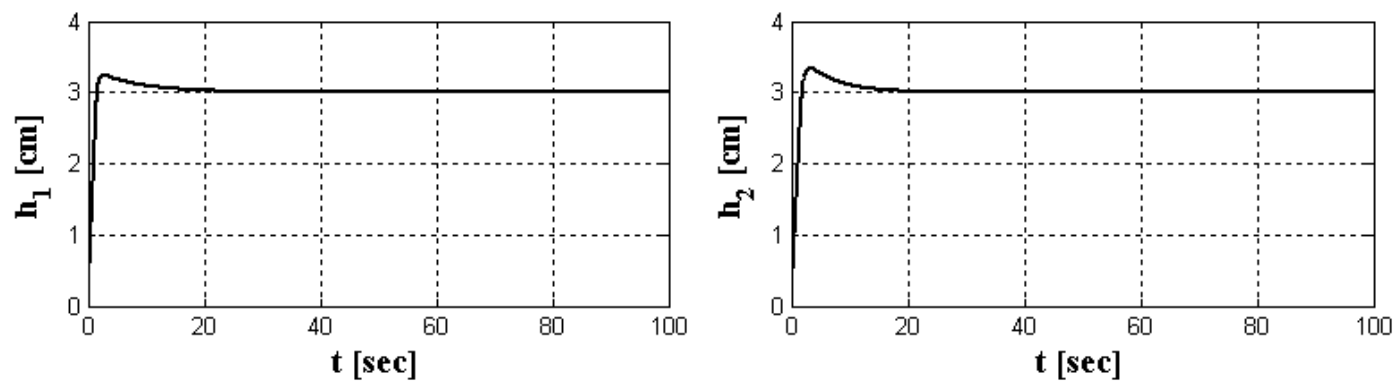

(a)
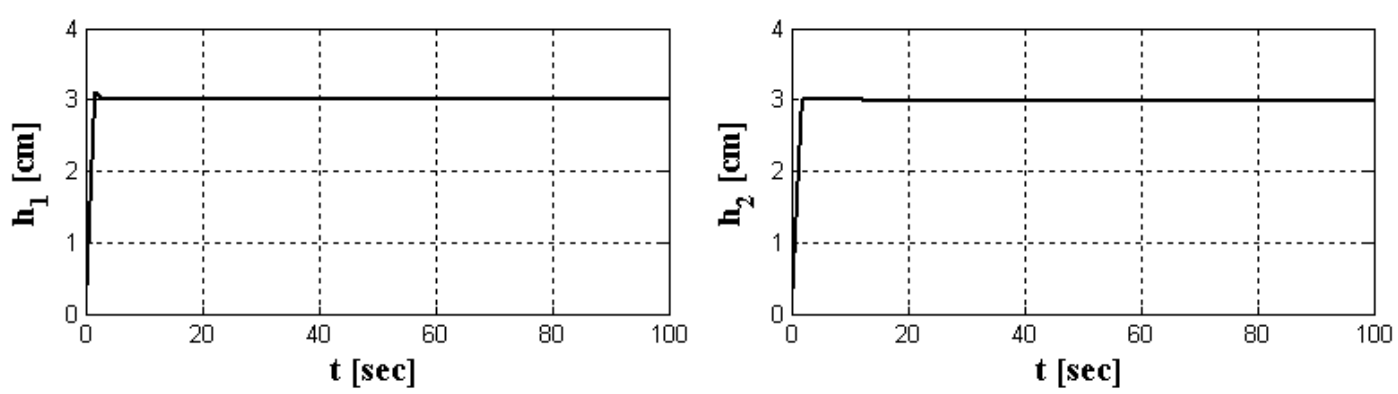

(b)

Figure 10. Output response of the QTP: (a) PI controller and (b) NFLC
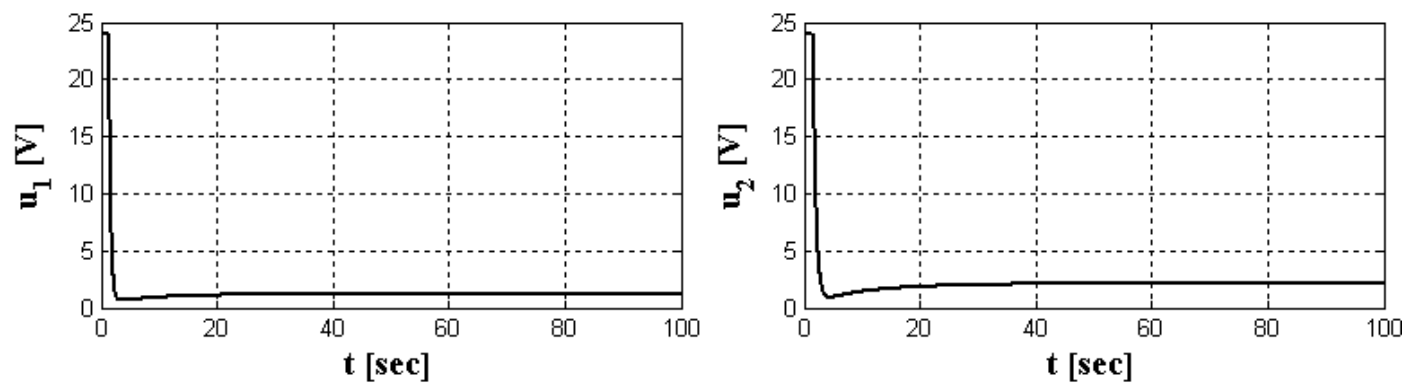

(a)
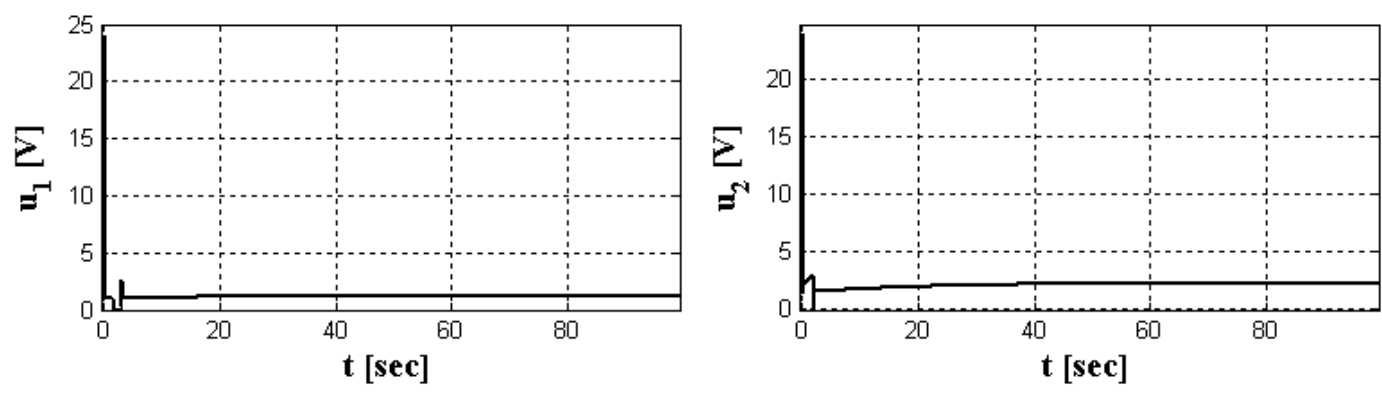

(b)

Figure 11. Control signals of the QTP: (a) PI controller and (b) NFLC

\section{CONCLUSION}

An NFLC strategy for controlling QTP is presented in this study. The objective of this research is achieved by maintaining the required water level (as indicated by the reference water level). The proposed controller is implemented using MATLB®/SIMULINK®. The numerical simulation denotes that the 
performance of the NFLC is superior in terms of reference follow-up. Moreover, the energy delivered by the controller is better than that of the conventional method.

\section{REFERENCES}

[1] E. G. Kumar, B. Mithunchakravarthi, and N. Dhivya, "Enhancement of PID Controller Performance for a Quadruple Tank Process with Minimum and Non-Minimum Phase Behaviors," Procedia Technol., vol. 14, pp. 480-489, 2014.

[2] N. Z. Abidin, S. Sahlan, and N. A. Wahab, "Optimization tuning of PI controller of quadruple tank process," in $3 r d$ Australian Control Conference, AUCC 2013, 2013, pp. 331-335.

[3] P. Srinivasarao and P. Subbaiah, "Tuning of nonlinear model predictive control for quadruple tank process," J. Theor. Appl. Inf. Technol., vol. 67, no. 2, pp. 316-326, 2014.

[4] P. Srinivasarao and P. Subbaiah, "Centralized and Decentralized of Quadruple Tank Process," Int. J. Comput. Appl., vol. 68, no. 15, pp. 21-29, 2013.

[5] P. Srinivasarao and P. Subbaiah, "Linear and non-linear model predictive control of quadruple tank process," Int. J. Comput. Appl., vol. 66, no. 20, pp. 28-34, 2013.

[6] A. Soldevila, J. F. Cayero Becerra, J. C. Salazar Cortés, D. Rotondo, and V. Puig Cayuela, "Control of a quadruple tank process using a mixed economic and standard MPC," in XXXV Jornadas de AutomàticaAt: Valencia, Spain, 2014, pp. 3-5.

[7] N. Muthukumar, V. Gomathi, K. Ramkumar, and G. Balasubramanian, "Prediction based optimal control of a quadruple tank process," in IEEE International Conference on Circuit, Power and Computing Technologies, ICCPCT 2013, 2013, pp. 685-690.

[8] V. Kirubakaran, T. K. Radhakrishnan, and N. Sivakumaran, "Distributed multiparametric model predictive control design for a quadruple tank process," Meas. J. Int. Meas. Confed., vol. 47, no. 1, pp. 841-854, 2014.

[9] Z. Li and C. Zheng, "Holoop shaping control for quadruple tank system," in 6th International Conference on Intelligent Human-Machine Systems and Cybernetics, IHMSC 2014, 2014, pp. 117-120.

[10] G. Prakash and V. Alamelumangai, "Design of predictive fractional order PI controller for the quadruple tank process," WSEAS Trans. Syst. Control, vol. 10, pp. 85-94, 2015.

[11] I. Birs, C. Muresan, I. Nascu, and C. Ionescu, "A Survey of Recent Advances in Fractional Order Control for Time Delay Systems,” IEEE Access, vol. 7, pp. 30951-30965, 2019.

[12] C. Komathi, E. Vaishali, and M. Sobitha, "Performance Optimization of a Decoupled Quadruple Tank System Using Fractional Order Proportional Integral Controller .," Int. J. Electron. Electr. Comput. Syst., vol. 6, no. 11, pp. 258-265, 2017.

[13] K. Sundaravadivu, V. Jeyakumar, and K. Saravanan, "Design of Fractional Order PI controller for liquid level control of spherical tank modeled as Fractional Order System," in Proceedings - 2011 IEEE International Conference on Control System, Computing and Engineering, ICCSCE 2011, 2011, pp. 522-525.

[14] U. S. Banu and S. K. Lakshmanaprabu, "Adaptive multi-loop fractional order PID controller tuning using Bat colony optimization for Quadruple Tank process," in International Conference on Robotics, Automation, Control and Embedded Systems (RACE), 2015, pp. 1-8.

[15] G. K. E and J. Arunshankar, "Control of nonlinear two-tank hybrid system using sliding mode controller with fractional-order PI-D sliding surface,” Comput. Electr. Eng., vol. 71, pp. 953-965, 2018.

[16] S. Sutha, P. Lakshmi, and S. Sankaranarayanan, "Fractional-order sliding mode controller design for a modified quadruple tank process via multi-level switching," Comput. Electr. Eng., vol. 45, pp. 10-21, 2015.

[17] A. Turki, S. H. Said, and F. M'Sahli, "Backstepping control for a quadruple tank process based on adaptive observer," in 12th International Multi-Conference on Systems, Signals and Devices, SSD 2015, 2015, pp. 1-5.

[18] S. Ahmed, I. Ganchev, A. Taneva, and M. Petrov, "Decoupling neuro-fuzzy model predictive controllers applied to quadruple tanks," in 8th IEEE International Conference on Intelligent Systems, IS 2016 - Proceedings, 2016, pp. $610-615$.

[19] C. M. Ionescu, A. Maxim, C. Copot, and R. De Keyser, "Robust PID Auto-tuning for the Quadruple Tank System," IFAC-PapersOnLine, vol. 49, no. 7, pp. 919-924, 2016.

[20] V. Kirubakaran, T. K. Radhakrishnan, and N. Sivakumaran, "Fuzzy aggregation based multiple models explicit multi parametric MPC design for a quadruple tank process," IFAC-PapersOnLine, vol. 49, no. 1, pp. 555-560, 2016.

[21] P. Roy and B. K. Roy, "Dual mode adaptive fractional order PI controller with feedforward controller based on variable parameter model for quadruple tank process," ISA Trans., vol. 63, pp. 365-376, 2016.

[22] R. E. Ak and M. Baihaqi, "Linearization and Decoupling Controller for Quadruple Tank," in International Seminar on Intelligent Technology and Its Applications (ISITIA), 2017, pp. 233-237.

[23] S. Rajan and S. Sahadev, "Performance Improvement of Fuzzy Logic Controller Using Neural Network," Procedia Technol., vol. 24, pp. 704-714, 2016.

[24] M. P. Susmita Mishra, "Study of Fuzzy Logic in Medical Data Analytics," Int. Jiournal Pure Appl. Math., vol. 119, no. 12, pp. 16321-16342, 2018.

[25] H. M. Khan, G. Y. Chan, and F. F. Chua, "A fuzzy model for detecting and predicting cloud quality of service violation,” J. Eng. Sci. Technol., vol. 13, pp. 58-77, 2018.

[26] B. Sarwar, I. S. Bajwa, S. Ramzan, B. Ramzan, and M. Kausar, "Design and application of fuzzy logic based fire monitoring and warning systems for smart buildings," Symmetry (Basel)., vol. 10, no. 11, 2018. 